\title{
Small Ruminant Fasciolosis and its Direct Financial Loss in Dessie Municipal Abattoir North Eastern Ethiopia
}

\author{
Netsanet Berhe $^{1}$, Yalew Tefera ${ }^{{ }^{\star}}$, Tarekegn Tintagu ${ }^{1}$ and Wedajo Muleta ${ }^{2}$
}

${ }^{1}$ School of Veterinary Medicine, Wollo University, Dessie, Ethiopia

${ }^{2}$ Kombolcha Agriculture College, Kombolcha, Ethiopia

"Corresponding author: Yalew Tefera, School of Veterinary Medicine, Wollo University, Dessie, Ethiopia, Tel: 033-311-5204; E-mail: Yalewaykerm@gmail.com

Rec date: September 15, 2017; Acc date: November 22, 2017; Pub date: November 23, 2017

Copyright: (C) 2017 Berhe N, et al. This is an open-access article distributed under the terms of the Creative Commons Attribution License, which permits unrestricted use, distribution, and reproduction in any medium, provided the original author and source are credited.

\begin{abstract}
A cross sectional study was conducted from November 2016 to April 2017 on 384 small ruminants brought for slaughter to Dessie Municipal Abattoir from Dessie and its surroundings. Coprological and postmortem examinations were employed. The objectives of the study were to determine the prevalence of fasciolosis and associated risk factors, the test agreement between fecal examination by sedimentation and post mortem examination; and the direct financial loss due to liver condemnation. Of 384 fecal samples collected during ante mortem, 54 were positive for egg of Fasciola with an overall prevalence of $14.1 \%$ (54/384) based on coprological examination. The prevalence was $14.5 \%(50 / 294)$ in sheep and $10 \%(4 / 40)$ in goats. An overall prevalence of $18.8 \%(72 / 384)$ was found based on liver examination. There was no statistically significant difference $(P>0.05)$ in infection rate between the two species and sex. The difference in infection rate in body condition, age and fecal consistency was statistically significant $(\mathrm{P}=0.000,0.034$ and 0.031 respectively). The dominant species of Fasciola was $F$. hepatica $9.9 \%$, followed by 3.39 , 3.13 and $2.34 \%$ by immature Fasciola, F. gigantica and mixed infection respectively. The mean fluke burden was 28.28 ranging between 3 and 96 flukes per infected liver and the fluke burden was highest in animals with mixed infection followed by animals infected by $F$. hepatica. The sensitivity of the sedimentation technique to detect Fasciola eggs was $75 \%$ compared to postmortem examination of liver and a considerable agreement (kappa $=0.830$ ) was obtained between the tests. An annual loss of 25230 Birr loss was estimated in Dessie Municipal Abattoir. Study on public health implication of the parasites is recommended.
\end{abstract}

Keywords: Dessie municipal abattoir; Fasciola; Prevalence; Risk factor

\section{Introduction}

Fasciolosis is an economically important disease of livestock, in particular cattle and sheep. The disease is caused by digenean trematodes of the genus Fasciola, commonly referred to as liver flukes. The two species most commonly implicated as the etiological agents of fasciolosis are $F$. hepatica and $F$ gigantica. F. hepatica has a worldwide distribution but predominates in temperate zones while $F$. gigantica is found on most continents, primarily in tropical regions [1].

The snail of the genus Lymnae natalensis and Lymnae truncatula are known as intermediate host in life cycle of fasciolosis. Infection with Lymnaea truncatula is usually associated with herds and flocks grazing in wet marshy land [2].

In Ethiopia, sheep and goats are important livestock sector with the population of 58 million [3], providing up to $63 \%$ of cash income and $23 \%$ of food substance value obtained from livestock production. Despite all the contribution of this sub-sector to the country economy, attention given towards health management is relatively low. Endoparasitic infection and management problems are known to be the main factors that affect productivity [4]. Economic losses resulting from mortality and morbidity (reduced meat, milk and wool production and reproductive inefficiency) impose serious limitations on small ruminant production in Ethiopia [5].
Since Fasciolosis is major parasitic disease of small ruminants, an estimate of economic loss due to ovine fasciolosis in the Ethiopia highlands was made based on available data on mortality, weight loss, reduced reproduction efficiency and liver condemnation at slaughter. The economic effects of fasciolosis were identified and models for estimating the financial loss presented [6].

The public health importance of human fascioliasis has, however, increased in recent years, as shown by the high number of human cases recorded over the period 1970-1990: 2594 infected persons in 42 countries located on all continents [7]. Humans can become infected after consumption of aquatic plants that contain the infective metacercariae [8]. In Ethiopia the prevalence of fasciolosis is as high as $83.08 \%$ [9] in cattle, $62.7 \%$ [10] in sheep and $17.2 \%$ [11] in goats. Even though different researches have been done in other areas in Ethiopia, small ruminant fasciolosis prevalence in Dessie area has not been studied and there is no published data. The objectives of this research work were to determine the prevalence of fasciolosis based on fecal examination and post mortem examination, to assess the associated risk factor, to evaluate the test agreement between fecal examination by sedimentation and post mortem examination and to assess the direct financial loss due to fasciolosis as cause of liver condemnation

\section{Materials and Methods}

\section{Study area}

The study was conducted from November 2016 to April 2017 in Dessie Municipal Abattoir. Dessie is located North East Ethiopia at a 
distance of $400 \mathrm{~km}$ from Addis Abeba, at $11^{\circ} 08^{\prime}$ North latitude and $39^{\circ} 38^{\prime}$ East longitude and has an elevation of $2600 \mathrm{~m}$ above sea level. The mean minimum and maximum temperature are $12.37^{\circ} \mathrm{C}$ and $26.27^{\circ} \mathrm{C}$, respectively [12].

\section{Study population and study animals}

The study populations were all ages and sex groups of indigenous breeds of sheep and goats which were brought from mainly Dessie and its surrounding. The livestock population of the area comprises 18,724 cattle, 22,248 sheep, 2,572 goats, 1,879 horses, 833 mules, 3,362 donkeys and 37,557 heads of chickens [12].

Study design and sampling methods: A cross-sectional type of study design was carried out to investigate the prevalence and risk factors for Fasciola infection in small ruminants in Dessie Municipal Abattoir.

Animals included in the study were selected using random sampling method from the sheep and goats presented to be slaughtered at the Dessie Municipal Abattoir.

The sample size for the study was calculated using the formula given by Thrusfield [13]. For calculating the required sample size, $95 \%$ confidence interval (CI) and 5\% absolute level of precision was used. Since there was no pervious study conducted on small ruminant fasciolosis in the study area, 50\% expected prevalence was taken.

$$
\mathrm{N}=1.962 \times \mathrm{P}_{\exp }\left(1-\mathrm{P}_{\exp }\right) / \mathrm{d}^{2}
$$

Where $\mathrm{n}=$ required sample size, $\mathrm{d}=$ desired absolute precision 0.05 , $\mathrm{P}_{\text {exp }}=$ expected prevalence $(50 \%)$.

Accordingly, the sample size was calculated to be 384 (both sheep and goats). But, due to the fact that, few goats were brought for slaughter during the study period, only 40 goats and 244 sheep were included in this study.

\section{Methodology}

Ante mortem examination: During ante mortem examination, identification numbers were given to the study animals and their ages were recorded by looking the appearance of the incisor teeth [14]. Information regarding sex, age and body condition of the study animals was recorded during ante-mortem examination. Body condition score of the animals was scored following the guidelines set by Villaquiran [15] by modifying the 1-5 scoring in to 3 only (poor, medium and good body condition). The nature of the feces or fecal consistency was recorded as normal (pellet), soft or diahrric while taking fecal samples during ante mortem examination. Finally, before the selected animals are slaughtered, fresh fecal sample was collected directly from rectum and kept in separate glass or plastic container with individual animal identification number.

Coprological examination: Each samples of 20-25 g of fecal material was collected directly from the rectum of each animal or freshly defecated faeces in to plastic bottle with gloved hand. The samples were clearly labeled with universal bottles preserved with $10 \%$ formalin and each sample was clearly labeled with animal's identification (species, age, sex), date of collection. Samples were packed and transported in cool box to avoid development of eggs and hatching. After the samples are taken to Wollo University, school of veterinary medicine veterinary parasitology laboratory, coprospic examination was performed to detect the presence of Fasciola eggs using the standard sedimentation techniques [16]. For the purpose of differentiating between eggs of paramphistomum species and Fasciola species, a drop of methylene blue solution was added to the sediment.

Liver examination: The liver of each study animal was carefully examined for presence of lesions suggestive of Fasciola infection externally and sliced for confirmation. Liver flukes were recovered for differential count by cutting the infected liver into fine, approximately $1 \mathrm{~cm}$, slices with a sharp knife according to [16]. Each mature fluke was identified to species level according to its shape and size [17]. The species identification was done as $F$. hepatica, $F$ gigantica, mixed (when both species are found) and immature. During liver examination all intact immature and mature flukes and only fluke heads when a portion of fluke was found were counted in determining the fluke burden of liver.

Estimation of financial loss due to liver condemnation: The total annual financial loss incurred due to liver condemnation at the Abattoir was computed by multiplying the average number of sheep and goats slaughtered annually in the Abattoir by the prevalence of fascioliasis obtained from the present survey and mean price of liver in the Dessie city. For each year, data were summarized to give the proportion of sheep and goat livers infected with Fasciola. Annual financial loss estimation was done for the losses due to liver condemnation based on average number of small ruminants slaughtered from 2006-2008 Ethiopian physical years' available complete data from Dessie Municipal Abattoir record. The total quantity of all costs was considered according to Ethiopian currency in birr. The direct financial losses incurred due to liver condemnation were estimated by using the formula indicated below [18].

$$
\mathrm{EL}=\left[\mathrm{S}_{\mathrm{SR}} \times \mathrm{OC}_{\mathrm{Li}} \times \mathrm{R}_{\mathrm{Li}}\right]
$$

Where: EL=Estimated annual economic loss due to liver condemnation, $\mathrm{S}_{\mathrm{SR}}=$ Annual shoats slaughter rate of the Abattoir, $\mathrm{OC}_{\mathrm{LI}}=$ Average cost of liver/cost of rejected liver, $\mathrm{R}_{\mathrm{Li}}=$ Rejection rate of liver.

All affected livers were condemned since partial approval was not practiced in the Abattoir. An interview was made with 6 retailers of offal produced at Dessie Municipal Abattoir and 6 individuals working for three restaurants in Dessie city to obtain information on the average price of a liver from sheep and goats. Accordingly, the average market price of sheep and goat liver was found to be 11.00 ETB.

\section{Data management and analysis}

Data collected for the study was entered into a Microsoft excel worksheet and analyzed using the SPSS software package (Version 20). The prevalence of fascioliasis was calculated as the number of animals infected by Fasciola divided by the total number of slaughtered animals multiplied by $100 . \mathrm{P}<0.05$ was considered for statistical significance. The sensitivity of the direct sedimentation technique was calculated by taking postmortem inspection of liver as gold standard. Kappa coefficient was used to compare the agreement between coprology and post mortem examination for diagnosis of fasciolosis.

\section{Results}

\section{Coprological examination result}

Out of 384 fecal samples collected during ante mortem, 54 were positive for egg of Fasciola with an overall prevalence of $14.1 \%$ (54/384) based on the coprological examination. The prevalence was $14.5 \%(50 / 294)$ in sheep and $10 \%(4 / 40)$ in goats (Table 1$)$. 
Page 3 of 5

\begin{tabular}{|l|l|l|l|l|}
\hline Species & $\begin{array}{l}\text { Number of } \\
\text { sampled } \\
\text { animals }\end{array}$ & $\begin{array}{l}\text { Number of } \\
\text { positive } \\
\text { animals }\end{array}$ & Prevalence (\%) & P-value \\
\hline Ovine & 344 & 50 & 14.5 & 0.435 \\
\hline Caprine & 40 & 4 & 10 & \\
\hline Total & 384 & 54 & 14.1 & \\
\hline
\end{tabular}

Table 1: Prevalence Fasciola in small ruminant based on coprological examination.

\section{Liver examination result}

Overall prevalence of fasciolosis: The livers of same animals from which fecal samples were taken before they are slaughtered were carefully examined for the presence of Fasciola parasites. An overall prevalence of $18.8 \%(72 / 384)$ was found based on liver examination. There was higher rate of infection in the sheep than goats but this difference was not statistically significance $(\mathrm{P}>0.05)$. Similarly there was no statistically significant difference in infection rate between the two sex groups.

The prevalence of fasciolosis was found to be higher in sheep and goat with poor body condition than those with medium and good body condition ones and the prevalence was $76.9 \%$ (40/52), $11.3 \%$ $(25 / 222)$ and $6.4 \%(7 / 110)$ in sheep and goat with poor body condition, medium and good body condition respectively. The difference in infection rate by body condition was statistically significant $(\mathrm{P}=0.000)$ (Table 2$)$.

As it can be seen in Table 2, sheep and goat within the age group less than 1 year and from 1 up to 2 years are more affected the sheep and goats greater than 2 years of age.

It was tried to analyze if there is association between consistency of feces of the sampled animals and infection rate by Fasciola parasite and there was association between fecal consistency (diarrheic, soft and pellet/normal) and fasciolosis in the study animals (Table 2).

On the other hand in present study area the prevalence of fasciolosis was found to be higher in sheep with poor body condition than those with medium and good body condition with a prevalence of $76.9 \%$ (40/52), 11.3\% (25/222) and 6.4\% (7/110) respectively (Table 2$)$.

\begin{tabular}{|c|c|c|c|c|c|}
\hline \multicolumn{2}{|l|}{ Variables } & $\begin{array}{l}\text { No of } \\
\text { examined }\end{array}$ & $\begin{array}{l}\text { No of } \\
\text { positive }\end{array}$ & $\begin{array}{l}\text { Prevalence } \\
\text { (\%) }\end{array}$ & $\begin{array}{l}\text { P- } \\
\text { Value }\end{array}$ \\
\hline \multirow{2}{*}{ Species } & Ovine & 344 & 68 & 19.8 & \multirow{2}{*}{0.134} \\
\hline & Caprine & 40 & 4 & 10 & \\
\hline \multirow{2}{*}{ Sex } & Female & 45 & 7 & 15.6 & \multirow{2}{*}{0.559} \\
\hline & Male & 339 & 65 & 19 & \\
\hline \multirow{3}{*}{ Age } & $<1$ year & 101 & 24 & 23.8 & \multirow{3}{*}{0.034} \\
\hline & $1-2$ years & 185 & 38 & 20.5 & \\
\hline & $>2$ years & 98 & 10 & 10.2 & \\
\hline \multirow{3}{*}{$\begin{array}{l}\text { Body } \\
\text { condition } \\
\text { score }\end{array}$} & Poor & 52 & 40 & 76.9 & \multirow{3}{*}{0} \\
\hline & Medium & 222 & 25 & 11.3 & \\
\hline & Good & 110 & 7 & 6.4 & \\
\hline
\end{tabular}

\begin{tabular}{|l|l|c|c|c|c|}
\hline \multirow{3}{*}{$\begin{array}{l}\text { Fecal } \\
\text { consistency }\end{array}$} & Diahrric & 18 & 4 & 22.2 & \\
\cline { 2 - 5 } & Soft & 42 & 14 & 33.3 & \multirow{2}{*}{0.031} \\
\cline { 2 - 5 } & Normal & 324 & 54 & 16.7 & \\
\hline & Total & 384 & 72 & 18.8 & \\
\hline
\end{tabular}

Table 2: Prevalence of fasciolosis by the different variables based on postmortem finding.

Fluke burden and species of Fasciola: The mean fluke burden was 28.28 ranging between 3 and 96 flukes per infected liver. Mean count was highest in animals with mixed infection 41.56 fluke per infected liver followed by animals infected by $F$. hepatica 32 flukes per infected liver. Of the 384 examined livers, 10.16, 4.9 and $3.9 \%$ had fluke counts between 3-20, 21-49 and 50-93 respectively. As indicated in Table 3, the overall prevalence of $F$. hepatica is $9.9 \%$ followed by $3.39,3.13$ and $2.34 \%$ by immature Fasciola, F. gigantica and mixed infection ( $F$. hepatica and F. gigantica species) respectively.

\begin{tabular}{|l|l|l|l|l|l|l|l|}
\hline $\begin{array}{l}\text { Spp of } \\
\text { Fasciola }\end{array}$ & $\begin{array}{l}\text { Prevalenc } \\
\mathbf{e} \%\end{array}$ & $\begin{array}{l}\text { Mea } \\
\mathbf{n}\end{array}$ & $\mathbf{N}$ & $\begin{array}{l}\text { Std. } \\
\text { Deviatio } \\
\mathbf{n}\end{array}$ & $\begin{array}{l}\text { Minimu } \\
\mathbf{m}\end{array}$ & $\begin{array}{l}\text { Maximu } \\
\mathbf{m}\end{array}$ & $\begin{array}{l}\text { \% of } \\
\text { Total } \\
\text { Sum }\end{array}$ \\
\hline $\begin{array}{l}\text { Fasciola } \\
\text { hepatica }\end{array}$ & $9.90 \%$ & 32 & 3 & 27.436 & 3 & 96 & $59.70 \%$ \\
\hline $\begin{array}{l}\text { Fasciola } \\
\text { gigantica }\end{array}$ & $3.13 \%$ & 13.75 & 1 & 22.479 & 3 & 82 & $8.10 \%$ \\
\hline $\begin{array}{l}\text { Mixed } \\
\text { infection }\end{array}$ & $2.34 \%$ & 41.56 & 9 & 22.154 & 17 & 75 & $18.40 \%$ \\
\hline $\begin{array}{l}\text { Immatur } \\
\text { e } \\
\text { Fasciola }\end{array}$ & $3.39 \%$ & 21.62 & 1 & 23.786 & 4 & 75 & $13.80 \%$ \\
\hline Total & $18.80 \%$ & 28.28 & 7 & 26.364 & 3 & 96 & 100.00 \\
\hline
\end{tabular}

Table 3: Fluke burden and prevalence by the different Fasciola species.

Sensitivity of sedimentation method for detection of Fasciola eggs: From the 72 small ruminants that had flukes in their livers, only 54 showed Fasciola eggs in their feces. The sensitivity of coprological examination by sedimentation was $75 \%$. There was substantial agreement between the two tests $(\mathrm{k}=0.830)$ (Table 4$)$ below.

\begin{tabular}{|l|l|l|l|l|}
\hline \multirow{2}{*}{ Fecal examination } & \multicolumn{2}{|l|}{ Post mortem examination } & Total & \multirow{2}{*}{ Kappa } \\
\cline { 2 - 5 } & Negative & Positive & \multicolumn{2}{|c|}{} \\
\hline Negative & 312 & 18 & 330 & \multirow{2}{*}{0.83} \\
\hline Positive & 0 & 54 & 54 & \\
\hline Total & 312 & 72 & 384 & \\
\hline
\end{tabular}

Table 4: Sensitivity of coprological examination by sedimentation for detection of Fasciola eggs.

\section{Financial loss estimation due to liver condemnation}

Based on the prevalence of fasciolosis determine by this study, the annual slaughter rate of Dessie municipal abattoir and current market 
price of sheep and goat liver in Dessie town the direct financial loss due to liver condemnation was estimated to be 25230 birr annually.

\section{Discussion}

Fasciolosis is an existing ruminant health concern and causes substantial economic losses to the livestock commerce in Ethiopia. The overall prevalence of Fasciola spp infection in small ruminants observed in this study was $18.8 \%$ and on animal species basis, the prevalence was $19.8 \%$ in sheep and $10 \%$ in goats without statistically significance difference between the two species $(\mathrm{P}>0.05)$. The current prevalence observed in sheep was higher than that reported by previous similar studies in Hawassa district with the total prevalence of $9.8 \%$ in small ruminants, $12 \%$ in sheep and $7.5 \%$ in goats [19]. However very higher prevalence than the present study was reported by Hassan [20] 49\% in and around DawaCheffa, Kemissei area, by Bogale [21] 39.5\% in Adigrat and Mulatu [22] 43.75\% in Haru district, western Ethiopia. This clear and high variation was probably due to the difference in agro-climatic conditions conducive for the intermediate host and the parasite.

Solomon, has reported statistically significant difference in the prevalence of fasciolosis between sheep and goats being high in sheep [23]. In contrast this other previous works, in the present study, the difference in infection rate by Fasciola was not statistically significant $(\mathrm{P}>0.05)$ between sheep and goats although sheep were affected at higher rate. There is a general understanding that sheep and goats differ in their feeding habits. Naturally, goats depend on browsing plants for their nutrition and thus, they are less exposed to the infective larval stages of parasites including Fasciola spp. In spite of this fact, nowadays in Ethiopia goats had changed their feeding behavior from browsing to grazing on the same pasture along with sheep because of shortage of browsing plants associated with bush clearing for expansion of crop agriculture and human settlement. This had resulted in equal exposure of goats to infective larval stages of Fasciola spp to similar level of infection as in sheep [24].

In this study the result indicated that there is statistically significant difference $(\mathrm{P}=0.000)$ in infection rate with Fasciola between sheep and goats with poor body condition and medium/good body condition. This indicates that fasciolosis leads to body weight loss or reduction in body weight gain in infected animals. This could be also because of increased susceptibility of animals with poor body condition to fasciolosis and other infection than animals with medium and good body condign. The significant variation in the prevalence of Fasciola infection in relation to body condition could be further explained by the fact that as the body condition improves, infection with Fasciola decreased because Fasciola worms are known to suck blood and tissue fluid and even damage the parenchyma of the liver due to the migrating immature worms [25].

Dagnachew has suggested that fascioliasis equally affect both sexes. In agreement to this, in the present study, there is no statistically significant difference $(\mathrm{P}>0.05)$ in the prevalence of fasciolosis between the two sexes groups [26]. This might be because both sexes were grazing in similar pastureland having equal access for the infection.

In the present study, prevalence of Fasciola was significant higher in age group $<1$ year than in 1-2 years and above 2 years of sheep and goats. There are reports of higher prevalence in young animals was but limited to areas where fasciolosis was hyper-endemic and animals get infection shortly after birth. Hence, reason for the higher prevalence in sheep and goats less than one year of age could be due to the endemic nature of fasciolosis in the study area. Ahmed reported higher prevalence in young animals [27]. The results of this study are not in agreement with the findings of Bitew, Mbaya and Oyeduntan [28-30].

The species of Fasciola identified in this study were Fasciola hepatica $9.9 \%$, Fasciola gigantica $3.13 \%$ mixed infection $2.34 \%$ and immature Fasciola which were difficult to identify $3.39 \%$. The relative prevalence of the Fasciola species was 59.7\% Fasciola hepatica $8.1 \%$ Fasciola gigantica $18.4 \%$ mixed infection and $13.8 \%$ immature.

A study on fluke count revealed a mean fluke burden of 28.28 per infected liver. This implies high pathogenicity of liver flukes and significant economic importance in the study area. In this study, $20.83 \%(15 / 72)$ infected liver had fluke count of 50-93. More than 40 and 50 flukes per liver indicate a high pathogenicity in small ruminants and cattle, respectively [17]. Significant production losses also reported in infections with 30 flukes per liver [31]. A higher fluke mean count 49 per infected liver has been reported by Ogunrinade [11] from Jimma in small ruminants.

The sensitivity of coprologic examination of feces by sedimentation was determined using postmortem examination (liver examination) as golden standard. The sensitivity of coprologic examination of feces by sedimentation was $75 \%$ with kappa value of 0.830 . $66.5 \%$ sensitivity which is lower than the present study finding has been reported by Ngategize [32] as sensitivity of fecal egg detection by sedimentation. But the comparison was done by using agar gel precipitation test (AGPT) as golden standard test. In another but similar study with the current, $55.28 \%$ sensitivity of sedimentation technique to detect Fasciola eggs was as compared to detection of fasciolosis by postmortem examination of liver [11]. The measure of agreement kappa value reputed by these researchers was 0.653 .

In Ethiopia, the annual economic losses due to ovine fascioliasis were estimated at 48.4 million Ethiopian Birr, of which 46.5, 48.8, and $4.7 \%$ were due to mortality, productivity (weight loss and reproductive wastage), and liver condemnation at slaughter, respectively [3]. In the present study an annual loss of 25230 Birr this value of loss estimated in Dessie municipal abattoir is fairly huge loss as this loss is only due to liver condemnation and it is in a single abattoir. 21,045.9 ETB loss due to liver condemnation which is comparable with the present study was reported by Ogunrinade [11]. On another report an annual loss 106,536.9 ETB per year huge financial loss was reported by Nebyou [33] from Nekemte. The difference in the financial loss estimated in various abattoirs may be due to the variation in the prevalence of disease, mean annual number of animals slaughtered in different abettor and also the variation in the retail market price of organs.

\section{Conclusion and Recommendations}

Fasciolosis is an important helminth disease and one of the major obstacles for livestock development in Ethiopia causing remarkable direct and indirect losses in different parts of the country. This study has investigated the prevalence of fasciolosis in sheep and goats in Dessie municipal abattoir about $14.1 \%$. Prevalence of fasciolosis based on coprological examination by sedimentation and $18.8 \%$ by postmortem examination. Body condition, age and fecal consistency are highly associated with fasciolosis in small ruminants in the study area. Sheep and goat with poor body condition and those young less than one year are significantly affected by fasciolosis. Both species of Fasciola are identified $F$. hepatica being the predominant in the area. Most of the animals were positive for coprological examination by sedimentation technique which from those which found positive by 
postmortem examination of the liver. This indicated the substantial test of agreement (kappa=0.830) and good sensitivity of sedimentation technique in detecting Fasciola egg. Hence, the present study suggests that further strategic control of snails is required in order to overcome the problems of ovine fasciolosis at the study area.

Therefore, based on the above findings the following recommendations are forwarded:

- Detailed study on the economic and public health implications of the parasite Fasciola species is recommended.

- Further study using alternative techniques such as serology in combination with fecal test surveys need to be conducted to generate more complete data on the prevalence of ovine fasciolosis

- Appropriate strategic deworming has to be designed and implemented in the study area to minimize the effect of the disease on livestock productivity.

- Strategic vectors control through different techniques should be undertaken so that minimize the risk of fasciolosis in the area in order to improve or boosting the livestock productivity of the study area.

\section{References}

1. Andrews SJ (1999) The Life Cycle of Fasciola hepatica. In: Dalton JP(ed.) Fasciolosis. CABI Publishing, pp: 1-29.

2. Payne WJ (1990) An introduction to Animal Husbandry in the tropics. 4th edn. Black Well Science. Oxford. London, Pp 47-74.

3. CSA, Central Statistical Authority (2015) Federal Democratic Republic of Ethiopia, Agricultural Sample Enumeration Statistical Abstract. Addis Ababa, Ethiopia.

4. Ahmed EF, Markvichitr K, Tumwasorn S, Koonawootrittriron S, Choothesa A, et al. (2007) Prevalence of Fasciola species infections of sheep in the middle awash river basin Ethiopia. Southeast Asian J Trop Med Public Health 38: 51-57.

5. Njau BC, Scholtens RG (1988) The role of traditionally harvested hay in the transmission of ovine fasciolosis in the Ethiopian highlands. Vet Res Commun 15: 369-372.

6. Anderson N, Luong TT, Bui KL, Smoker PM (1999) The sensitivity and specificity of two methods for detection Fasiola in cattle. Vet Parasitol 83: 15-24.

7. Chen MG, Mott KE (1990) Progress in assessment of morbidity due to Fasciola hepatica infection: a review of recent literature. Trop Dis Bult 87: 29-38.

8. Markell EK, Voge M (1999) Medical Parasitology. 8th edn. Saunders Company Publication, pp. 185-188.

9. Mulualem E (1998) Epidemiology of bovine fasciolosis in weredas of South Gonder administrative zone bordering Lake Tana. Eth J Vet 2: 1-14.

10. Zeleke G, Menkir S, Desta M (2013) Prevalence of ovine fasciolosis and its economic significance in Basona worana district, central Ethiopia. Sci J Zool 2: 232-293.

11. Ogunrinade A, Ogunrinade BI (1980) Economic importance of bovine fasiolosis in Nigeria. Trop Anim Health Prod 12: 155-160.

12. DFEDB, Dessie Finance and Economic Development Bureau (2015) Overall Environmental Condition and Livestock Wealth Assessment of Dessie. Annual Report, pp: 28-36.

13. Thrusfield M (2005) Survey in Veterinary Epidemiology. 2nd edn Blackwell Science Ltd, Oxford, pp: 178-198.
14. Sanchez-Andrade R, Paz-Silva A, Suaurez JL, Panadero R, Pedreira J, et al. (2002) Influence of age and breed on natural bovine fasciolosis in an endemic area (Galicia, NW Spain). Vet Res Commun 26: 361-370.

15. Villaquiran M, Gipson TA, Merkel RC, Goetsch AL, Sahlu T (2017) Body Condition Scores in Goats American institute of goat research. Accessed on $01 / 09 / 2017$.

16. Soulsby EJL (1982) Helminths, Arthropods and Protozoa of Domesticated Animals. 7th edn. Balliere Tindall, London, UK, pp: 40-52.

17. Vercruysse J, Claerebout E (2001) Treatment vs. non-treatment of helminth infections in cattle: defining the thresholds. Vet Parasitol 98: 195-214.

18. Gebre Izgabeher E, Amede Y, Bekele M (2012) Prevalence of ovine fasciolosis in Adigrat, North East Ethiopia. Glob Vet 9: 92-96.

19. Marquardt WC, Demaree RS, Grieve RB (2000) Parasitology and Vector Biology. 2nd edn. Academic Press, London, pp: 273-279, 702.

20. Hassan MM, Hoque SK, Islam MA, Khan SA, Roy K, et al. (2011) A prevalence of parasites in black Bengal goats in Chittagong, Bangladesh. Int J Livest Prod 2: 40-44.

21. Bogale B, Keno D, Chanie M (2012) Ovine fasciolosis. episode and major determinants in Haru District, Western Ethiopia. Acta Parasitol Globalis 3: 07-11.

22. Mulatu H, Addis M (2011) Study on the prevalence and risk factors of fasciolosis in small ruminants in and around Hirna town, Ethiopia. Glob Vet 7: 497-501.

23. Solomon M, Eyob M, Rahmeto A (2014) Epidemiological Survey on Small Ruminant Fasciolosis in Hawassa Zuria and Dale Districts, Sidama Zone, Southern Ethiopia. Afr J Basic Appl Sci 6: 43-49.

24. Marquardt WC, Demaree RS, Grieve RB (2000) Parasitology and Vector Biology. 2nd edn. Academic Press, London, pp: 273-279, 702.

25. Solomon W (2005) Effect of strategic anthelmintic treatment intervention on ruminant fasciolosis in Upper Blue Nile Basin, North Western Ethiopia. Addis Ababa: Addis Ababa University, p: 78.

26. Dagnachew S, Mamute AA, Temesgen W (2011) Epidemiology of gastrointestinal helminthiasis of small ruminants in selected sites of North Gondar zone, Northwest Ethiopia. Eth Vet J 15: 57-68.

27. Ahmed M (2012) Slaughter house based epidemiology of Fascioliasis in small ruminants and comparative efficacy of commercial fasciolicides in district Sargodha. MSc. Thesis, Department of Parasitology, Faculty of Veterinary Sciences, University of Agriculture, Faisalabad.

28. Bitew M, Ibrahim N, Abdela N (2010) Study on the prevalence of ovine fasciolosis in and around Dawa-Cheffa, Kemissei. Afr J Agr Res 5: 2981-2985.

29. Mbaya AW, Shingu P, Luka J (2010) A retrospective study on the prevalence of Fasciola infection in sheep and goats at slaughter and associated economic losses from condemnation of infected liver in maiduguri abattoir, Nigeria. Nig Vet J 3: 224-228.

30. Oyeduntan AA, Adekunle BA, Benjamin OF (2008) A comparative study of three methods for detecting Fasciola infections in Nigerian cattle. Veterinarski Arhiv 78: 411-416.

31. Sirajudin K, Benti D, Worku T (2012) Small ruminant fasciolosis in Jimma area of South western Ethiopia: Its epidemiology and minimum monetary loss. Glob Veterinaria 9: 635-641.

32. Ngategize PK, Bekele T, Tilahn G (1993) Financial losses caused by ovine fascioliasis in the Ethiopian Highlands. Trop Anim Hlth Prod 25: 155-161.

33. Nebyou M, Debela A, Solomon K, Tesema T, Fanta D, et al. (2014) Major Causes of Organs and Carcass Condemnationin Cattle Slaughtered at Nekemte Municipality Abattoir, East Wollega, Ethiopia. Glob Vet 13: 278-284. 